\title{
Construções de Significados acerca do Adoecimento e Morte nas Narrativas de Crianças com Câncer
}

\section{Construction of Meanings about Illness and Death in the Narratives of Children with Cancer}

\author{
Ana Maria de Aquino ${ }^{a}$, Luciane De Conti* ${ }^{*}$ \& Arli Pedrosa ${ }^{b}$ \\ ${ }^{a}$ Universidade Federal do Rio Grande do Sul, Porto Alegre, Rio Grande do Sul, Brasil \\ $\&{ }^{b}$ Instituto de Medicina Integral Prof. Fernando Figueira, Recife, Pernambuco, Brasil
}

\begin{abstract}
Resumo
As narrativas surgem para ordenar a experiência humana alterada pela ruptura no seu estado canônico. Nesse sentido, uma doença como o câncer pode ser considerada uma experiência excepcional, que requer a narrativa para significá-la. Esse estudo investigou a construção de significados acerca do adoecimento e da morte nas narrativas de crianças com câncer em etapas distintas do tratamento. Para tanto, foram realizadas seis sessões de brincadeira com cada participante. A análise dos dados demonstrou que crianças com mais tempo de tratamento tendem a finalizar suas narrativas com a morte dos personagens e que crianças com menos tempo de tratamento apresentam narrativas relacionadas ao desconforto físico que o tratamento ocasiona e aos impedimentos que a doença acarreta em suas vidas. Esses resultados apontam para a necessidade de uma maior atenção à forma como as crianças falam do seu adoecimento e da subsequente possibilidade de morte no decorrer do tratamento oncológico, a fim de que possamos atentar para a diversidade dos momentos de tratamento, compreendendo que esses configuram diferentes relações subjetivas da criança para com sua doença e a morte.

Palavras-chave: Crianças com câncer, adoecimento, morte, construção de significados, narrativa.
\end{abstract}

\begin{abstract}
Narratives come out to arrange the human experience altered by the disruption in its canonical status. In this sense, a disease like cancer can be considered an exceptional experience that requires the narrative to mean it. This study investigated the construction of meanings about the disease and death in the narratives of children with cancer in different stages of treatment. Thus, six sessions of play were performed with each child. Data analysis showed that children in longer treatment tend to conclude their narratives with the death of the characters and the children under shorter treatment time present narratives related both to physical discomfort to which the treatment leads to and impairments that the disease cause in their lives. The results indicate the need for greater attention on how children talk about the disease and the subsequent possibility of death during the course of cancer treatment, so that we can be aware of the diversity of treatment moments, understanding that they configure different subjective relationships about children's health problem and death.

Keywords: Children with cancer, disease, death, construction of meaning, narrative.
\end{abstract}

Na Psicologia, em específico na área dos estudos da cognição, algumas das ideias que embasam a perspectiva narrativista têm como marca histórica a segunda revolução cognitiva (Moutinho \& De Conti, 2010). Essa revolução, segundo Bruner (1997a), objetivou trazer a mente de volta às ciências humanas. Para isso, ele propõe uma abordagem interpretativa da cognição em que o conceito central de uma psicologia humana seria o significado, juntamente com os processos e transações envolvidos na construção do mesmo. em Psicologia Cognitiva da Universidade Federal de Pernambuco, em junho de 2010, sob orientação da Profa. Dra. Luciane De Conti. Este estudo contou com o apoio financeiro do Conselho Nacional de Desenvolvimento Científico e Tecnológico $(\mathrm{CNPq})$ 
Nessa visão, a mente constitui e é constituída pela cultura, sendo a construção de significado a mediadora entre eles. A cultura, de acordo com Bruner (2001), funciona como um conjunto de ferramentas com técnicas e procedimentos que auxiliam o indivíduo a entender seu mundo e a lidar com ele. Bruner (1997a, 2003) diz que a cultura, através de seus mitos, histórias, dramas e cerimônias, cria as normas e suas violações, marca o que é esperado e define o que pode ser caracterizado como transgressão ou quebra do canônico.

A narrativa seria, então, a responsável pela interpretação da vida em ação e o princípio organizador da experiência humana, pois existe uma predisposição humana para ordenar a experiência em uma forma narrativa, em estruturas de enredo. A habilidade humana para organizar suas vivências na forma de histórias é viabilizada desde as primeiras interações entre a mãe e a criança (Macedo \& Sperb, 2007). Brockmeier e Harré (2003) argumentam que as crianças desde cedo são ensinadas a contar histórias e se, ao contá-las, não utilizarem devidamente as convenções, os ouvintes reclamam, param de ouvir. Perrone (1992) observou que comumente os adultos são os responsáveis por corrigir, completar e estimular as narrativas das crianças. A partir dos quatro anos a criança passa a tomar a iniciativa de relatar eventos passados independentemente da eliciação do adulto, o que significa um passo importante para a sua constituição como narrador.

Bruner (2003) propõe que a narrativa é constituída necessariamente por um cenário, por uma ação e por um ou mais personagens. O autor (1997a, 1997b) coloca que a narrativa é composta por uma sequência singular de eventos, estados mentais, ocorrências, envolvendo seres humanos como personagens ou autores. Cada um dos seus elementos constituintes adquirirá significação a partir do lugar que ocupa dentro do enredo da narrativa, ou seja, de sua sequência. Bruner (1997a) também propõe que uma das condições para que a composição narrativa se desenlace é a quebra do canônico, pois a narrativa é uma das modalidades de discurso que permite ao sujeito reordenar essa experiência desorganizadora.

Doenças crônicas, como o câncer, por exemplo, provocam rupturas na relação do ser humano com o seu mundo cotidiano, pois ao longo do processo da doença, a família e a criança enfrentam vários problemas como: "reinternações frequentes, terapêuticas agressivas, dificuldades de separação dos membros da família, alteração no cotidiano, limitações na compreensão do diagnóstico, desajuste financeiro, angústia, dor, sofrimento e medo constante da morte" (Silva, Andrade, Barbosa, Hoffmann, \& Macedo, 2009 , p. 335). Essas rupturas requerem a narrativa para significá-la, pois como afirmam Bruner (1997a) e Murray (2000), ela permite ao sujeito ordenar o caos que a doença provoca em sua vida.

No ato de contar histórias, as pessoas acometidas por uma doença passam a se conhecer melhor e a compreender as mudanças que estão ocorrendo em seus corpos. Hydén (1997) coloca que as narrativas dos pacientes dão voz ao sofrimento e a sua importância reside no fato de ela ser uma das principais formas de perceber, experienciar e julgar as ações e o valor de nossas vidas. Ela ajuda na construção de um novo contexto e organiza a ruptura causada pela doença colocando-a em uma estrutura, pois ao relacionar os sintomas da doença a outros eventos da vida, uma coerência é estabelecida. Nesse universo, é dada ênfase às formas que as narrativas assumem, suas representações e organizações, o que o narrador almeja expressar para outras pessoas e que muitas vezes não é ouvido. O interesse, então, passa a estar voltado não para o que as pessoas dizem, mas para o ‘como essas pessoas dizem'.

Nessa direção, Williams (1984) enfatiza o caráter biográfico da narrativa expandindo a compreensão da doença para além de suas causas. $\mathrm{O}$ autor enfatiza que a causalidade da doença precisa ser entendida em termos de reconstrução narrativa. Ele observou em seus estudos que as pessoas ao falarem acerca do que acreditavam ser a causa de suas doenças frequentemente incluíam em suas narrativas motivos pessoais para o seu adoecimento, a despeito do que os médicos podiam afirmar como sendo a causa de suas doenças. Para o autor, ao se entrelaçar os eventos ligados à doença com a vida pessoal, sintomas físicos são integrados à vida e diagnósticos e prognósticos adquirem significados dentro de um contexto da vida pessoal. Essa integração é fundamental para o processo de cura, uma vez que, como coloca Williams, a doença crônica altera a relação entre o corpo do paciente, seu self e o mundo à sua volta $\mathrm{e}$, ao descobrir meios de interpretar a doença, o indivíduo se torna capaz de restabelecer a relação entre ele mesmo, o mundo e o seu corpo.

Klein (2003) também enfatiza o benefício da narrativa em pessoas que viveram situações estressantes. A autora sugere que existe uma correlação entre construção narrativa e saúde, o que corrobora com o pensamento de que as narrativas trazem uma ordem para eventos desestruturantes na vida do indivíduo e que esta reorganização consequentemente traz efeitos positivos para a vida dessas pessoas. Herman (2003) e Mattingly (1998) também seguem esta mesma linha de raciocínio e apontam para o benefício do uso de histórias no contexto terapêutico. Nessa perspectiva, a narrativa funcionaria como um recurso básico da inteligência humana, como uma estratégia psicológica para se obter bem-estar após eventos traumáticos e estressantes. De acordo com Fonte (2006), o poder transformativo das narrativas reside na sua capacidade de re-narrar os acontecimentos da vida, atribuindo-lhes novos significados.

Em uma pesquisa com crianças, Dupas e Moreira (2003) compararam os significados de saúde e de doença atribuídos por crianças que se encontravam em ambiente hospitalar com as de ambiente escolar. Como resultado as autoras constataram que as crianças hospitalizadas partem da sua experiência, das mudanças que acontecem em seus corpos para, a partir disto, refletir sobre as possíveis causas de sua doença. A criança hospitalizada fala da doença enfatizando a sua própria doença e situação, enquanto que a criança na escola procura compreender a doença, 
Aquino, A. M., De Conti, L. \& Pedrosa, A. (2014). Construções de Significados acerca do Adoecimento e Morte nas Narrativas de Crianças com Câncer.

suas causas e consequências de forma desvinculada de qualquer experiência. $\mathrm{O}$ resultado dessa pesquisa mostra que esses relatos têm a função de organizar a experiência, atribuir-lhes significados, pois falar da doença dentro de um contexto da própria história de vida torna possível a atribuição de significados a eventos que interromperam e transformaram o curso da vida.

No que tange especificamente ao adoecimento por câncer, vários estudos (Angelo, Moreira, \& Rodrigues, 2010; Nehmy, Brito, Mota, \& Oliveira, 2011; Santo, Gaíva, Espinosa, Barbosa, \& Belasco, 2011; Woodgate, 2006) demonstram que as crianças e seus familiares enfrentam muitos desafios, tais como a multiplicidade de sentimentos, procedimentos e tratamentos invasivos, mudanças na rotina, nos papéis, nas relações e nas responsabilidades entre os membros da família. Duarte, Zanini e Nedel (2012) afirmam que os pais das crianças com câncer além de se confrontarem com a doença do filho, precisam lidar com as dificuldades econômicas decorrentes dos gastos com o tratamento e, muitas vezes, da perda do emprego, pois eles necessitam assumir integralmente os cuidados com a criança. Esses autores demarcam ainda que esses pais apresentam angústia frente à percepção de que o câncer pode levar seu filho à morte. Segundo eles, "esses sentimentos tornam-se mais evidentes conforme a gravidade da doença, tempo de permanência no hospital ou a possibilidade de recidiva" (p. 115).

A criança em tratamento, por sua vez, é exposta a internações periódicas que levam à interrupção da rotina escolar e social. Além disso, como afirmam Kohlsdorf e Costa (2011), os repetidos procedimentos médicos invasivos, como a quimioterapia, trazem efeitos colaterais diversos. Segundo Gomes, Amador e Collet (2012), entre os efeitos mais relatados pelas crianças estão náuseas, vômitos, aumento de peso, dor, reações de hipersensibilidade, fadiga e febre. Almeida (2005) afirma que além desses sintomas, a criança com câncer experimenta uma situação de contínuo enfrentamento com a morte devido ao tratamento prolongado, que é marcado por procedimentos invasivos e dolorosos, e ao falecimento de alguns colegas de enfermaria.

Dentre os estudos que abordam a problemática da criança e da morte, destacamos os realizados por Torres (2002) e por Torres, Guedes, Ebert e Torres (1998). Os autores, baseados na teoria de Piaget, colocam que o conceito de morte é algo complexo, multidimensional, que envolve subconceitos, sendo a universalidade, a não funcionalidade e a irreversibilidade os três componentes mais amplamente pesquisados. Segundo eles, a maioria dos estudos acerca da morte aponta para o fato de que as crianças nas fases iniciais do desenvolvimento frequentemente pensam sobre a morte como reversível, atribuem funções definidoras de vida às coisas mortas e não acreditam na inevitabilidade da morte. No que se refere à idade, a maioria das pesquisas sugere que a aquisição da percepção dos três componentes da morte - irreversibilidade, não funcionalidade e universalidade - situa-se em torno dos sete anos. Os resultados da pesquisa de Torres (2002) demonstram que a criança desde uma etapa muito precoce já possui uma representação da morte que vai gradualmente evoluindo, paralelamente ao desenvolvimento cognitivo.

De acordo com Kóvacs (1992) e Nunes, Carraro, Jou e Sperb (1998), a questão da origem da vida e da morte está presente no universo infantil desde muito cedo. O sentimento de morte para a criança não surge apenas quando ela se confronta com a morte de alguém, mas em diferentes situações de vida que configuram perdas ou frustração de expectativas, como o brinquedo quebrado ou perdido, o bichinho de estimação que fugiu, a separação dos pais, entre outros. Chiattone (2003), também investigando o conceito de morte em crianças, observou que crianças doentes e hospitalizadas apresentam precoce capacidade de percepção da morte, sugerindo que a vivência da doença, tratamento e evolução para a morte determinam antecipação da formação desse conceito.

Nessa direção, o estudo de Cagnin, Liston e Dupas (2004), realizado com crianças com câncer, demonstra que elas sabem da possibilidade da morte e que todo o sofrimento com o tratamento serve para reunir esforços necessários para garantir a vida. No entanto, as autoras também constataram que as crianças algumas vezes não conseguem avaliar a gravidade do seu caso em particular, adotando comportamentos de defesa contra as ameaças.

Em seu estudo sobre o a morte e o luto em crianças com câncer, Almeida (2005) observou que o tema da morte emergiu nas brincadeiras dessas crianças na forma de desejo em matar pessoas próximas como familiares e amigos ou da equipe médica. Também, segundo ela, as crianças expressavam em suas brincadeiras sentimentos de raiva e de agressividade ao se recusarem manusear ou ao tentar destruir brinquedos relacionados ao contexto hospitalar.

Tendo em vista a revisão da literatura, podemos perceber que o câncer é uma doença crônica que provoca mudanças drásticas no curso da vida da criança e de seus familiares. O seu simbolismo, como nos alertam Nehmy et al. (2011), remete ao sofrimento e à morte, algo que ataca a pessoa, que não há como controlar e cujo tratamento é drástico e muitas vezes sem sucesso. Neste cenário, a composição narrativa permitiria a essas pessoas construírem significados acerca da situação desestabilizadora do adoecimento. Além disso, como assinalam Duarte et al. (2012), o tempo de permanência no hospital e, portanto, de contato com a doença, modifica as expectativas dos sujeitos frente à mesma.

Assim, nosso estudo teve como objetivo investigar as construções de significados acerca do adoecimento e da morte nas narrativas de crianças com câncer em etapas distintas do tratamento oncológico. Para a realização do estudo, foram utilizadas as narrativas das crianças construídas no brincar, pois como alertam Goulart e Sperb (2003), a palavra nem sempre é eficaz para a expressão de sentimentos e afetos pela criança. As crianças, de acordo com Vieira e Sperb (1998), podem construir uma narrativa de diferentes formas, sendo os elementos acrescentados à 
história tanto pela via do brincar quanto por verbalizações, estando a linguagem presente na própria estrutura e organização narrativa do brincar.

Nicolopoulou (2005) afirma que o ponto de interseção entre o brincar e a narrativa é que a maior parte das brincadeiras simbólicas infantis centra-se em cenários narrativos. Para essa autora, é comum vermos as crianças imersas na brincadeira simbólica e ao mesmo tempo contando histórias como um modo complementar de sua atividade, em um contínuo arranjo. O brincar e a narrativa estão, assim, intimamente entrelaçados e frequentemente sobrepostos e ambos podem ser vistos como complementares da imaginação simbólica das crianças. Nessa pesquisa, por intermédio das narrativas construídas pelas crianças no brincar, objetivou-se investigar as versões das próprias crianças acerca do que estavam vivenciando com seu adoecimento por câncer.

\section{Método}

\section{Participantes e Contexto da Pesquisa}

Participaram da pesquisa seis crianças, todas com diagnóstico de Leucemia Linfóide Aguda (LLA), que estavam em tratamento no Centro de Hematologia e Oncologia Pediátrica (CEHOPE), vinculado ao Instituto de Medicina Integral Prof. Fernando Figueira (IMIP) - Unidade de Oncologia Pediátrica, em Recife. Após a confirmação do diagnóstico, uma equipe multiprofissional conversa com a criança e seus pais a fim de trazer informações sobre a patologia da criança, seu tratamento e prognóstico. Então, é iniciado o tratamento de quimioterapia em sistema ambulatorial. Após as sessões de quimioterapia, a criança pode retornar para casa, salvo quando está precisando de cuidados especiais.

As crianças estavam em fases distintas de tratamento do câncer. Três delas se encontravam em início de tratamento ( 0 a 6 meses de tratamento): C., menino, com nove anos de idade, proveniente da zona rural; S. e A., meninas, com sete anos, provenientes da região metropolitana. As outras três tinham de 1 a 2 anos de tratamento: U. e P., ambos meninos, com oito e nove anos respectivamente, provenientes da zona rural; e W., menino, com oito anos, residente na capital. Todas elas realizavam sessões de quimioterapia semanalmente e nenhuma das crianças havia sido submetida a transplante de medula óssea. As crianças provenientes da zona rural, quando precisavam ficar mais de um dia para a quimioterapia, ficavam abrigadas em uma instituição que fornece apoio à criança com câncer.

As leucemias agudas são doenças clonais do sistema hematopoiético que resultam da transformação maligna das células progenitoras hematopoiéticas em determinado estágio de maturação. Constituem um grupo heterogêneo de doenças, sendo o tipo mais comum de câncer na criança, representando $30 \%$ de todas as neoplasias malignas infantis, com uma incidência de 40 casos para cada 1.000.000 de crianças menores de 15 anos de idade. A LLA abarca cerca de $80 \%$ de todos os casos em crianças, o que a torna o câncer mais comum na faixa etária pediátrica e seu tratamento é prolongado, variando de dois a três anos (Nehmy et al., 2011).

\section{Delineamento e Procedimentos de Coleta de Dados}

$\mathrm{O}$ delineamento utilizado na pesquisa foi o de estudo de casos múltiplos conforme proposto por Yin (2001), em que cada criança constituiu um caso. Em relação à coleta de dados, primeiramente foi feito um contato presencial com a instituição para expor os objetivos da pesquisa e obter a autorização para a realização da mesma. Na sequência, a primeira autora deste artigo iniciou um período de familiarização na instituição, que teve duração de trinta dias, em que participou de alguns encontros dos grupos de terapia ocupacional com algumas crianças da instituição. Após esse período de familiarização, foram escolhidos os possíveis participantes da pesquisa através da lista das crianças que estavam em tratamento no CEHOPE e que tinham entre menos de um mês a dois anos de tratamento. Entre as crianças indicadas, foram pré-selecionadas aquelas que, segundo informações da equipe profissional da instituição, apresentavam um quadro geral de saúde mais estável e menos frágil.

Os pais dessas crianças foram contatados, sendo realizado o convite à participação na pesquisa e apresentados os objetivos do estudo. Seis pais concordaram que seu filho participasse do estudo e assinaram o Termo de Consentimento Livre e Esclarecido. Após a assinatura dos termos, a primeira autora realizou com os pais entrevistas semiestruturadas a fim de obter algumas informações prévias sobre as crianças, relacionadas ao contexto familiar, rotina da criança, possíveis internamentos antes do adoecimento por câncer ou possíveis experiências com morte de familiares ou pessoas próximas da criança. Também foi investigado junto aos pais se as crianças selecionadas sabiam o motivo de estarem na instituição e se tinham conhecimento da sua doença. Essas informações foram utilizadas para elucidar a história de vida da criança e complementar a análise das narrativas produzidas pelas crianças nas sessões de brincadeira.

Posteriormente às entrevistas com os pais, iniciaram-se as sessões de brincadeira com as crianças. No primeiro encontro com a criança a primeira autora se apresentava e explicava o motivo do encontro:

meu nome é Ana Maria, eu sou psicóloga e estou estudando para saber como é para você estar fazendo tratamento aqui, tendo que fazer quimioterapia . . . Como é que você se sente ... Aqui tem um bocado de brinquedo que a gente pode usar pra brincar, pra conversar ... A gente vai ter um total de seis encontros com mais ou menos 45 minutos de duração.

A pesquisadora, então, mostrava os objetos de brincar à criança e dizia que ela poderia escolher os brinquedos que quisesse. A partir do brincar livre da criança a pesquisadora interagiu quando solicitada e fez perguntas sobre as brincadeiras. Nessas sessões foram utilizados brinquedos à semelhança de pesquisa realizada por Goulart e Sperb 
Aquino, A. M., De Conti, L. \& Pedrosa, A. (2014). Construções de Significados acerca do Adoecimento e Morte nas Narrativas de Crianças com Câncer.

(2003), que são compostos por famílias de bonecos, animais, carrinhos, massinha de modelar e sucata de material hospitalar. Porém, acrescentamos a essa pesquisa os seguintes materiais: livros de histórias infantis, material para desenho e/ou escrita (folhas de papel ofício, caneta, lápis preto e de cor, canetinhas, giz de cera), jogos (Lego, jogos de montar).

Foram realizadas seis sessões de brincadeira com cada criança. Essas sessões geralmente ocorreram com frequência de uma sessão por semana, porém, em virtude das internações, sessões de quimioterapia e intercorrências sofridas por essas crianças, foi comum um intervalo maior entre as sessões. Cada sessão teve de 40 minutos a uma hora de duração. As sessões de brincadeira foram realizadas na sala de auditório da instituição, individualmente, foram filmadas e posteriormente transcritas visando-se à análise das narrativas.

\section{Procedimentos de Análise dos Dados}

Uma vez transcritas as sessões de brincadeira, desenvolveu-se dois tipos de análise, baseadas no modelo de análise de conteúdo proposto por Bardin (2008). Primeiramente, foi realizada a análise temática dos conteúdos verbais transcritos e, em um segundo momento, a análise da enunciação das narrativas compostas nessas sessões. Apesar de terem sido realizados dois tipos de análise, neste artigo será explanada apenas a análise da enunciação, uma vez que é nesta que o processo de construções de significados pode ser melhor evidenciado.

Para a análise da enunciação, foram retirados das sessões de brincadeira transcritas os episódios relacionados ao adoecimento e à morte. Esses episódios foram inicialmente analisados como sendo ou não uma narrativa. Para tanto, utilizou-se os critérios baseados em Bruner (1997a, 1997b) para definir uma narrativa, que são: (a) a narrativa acontece após a quebra de um estado esperado das coisas; e (b) possui como elementos constituintes: um cenário, uma ação e personagens.

$\mathrm{Na}$ análise da enunciação cada narrativa é estudada em si mesma como uma totalidade organizada e singular sendo considerados, nesse estudo, os seguintes níveis de análise: (a) dinâmica do discurso e (b) estudo das recorrências. A dinâmica do discurso é composta pela análise lógica de cada entrevista. A análise lógica é uma análise das relações entre proposições do discurso. Proposição é uma frase ou expressão que pronunciada sozinha fornece uma ideia ou mensagem. A primeira operação consiste em dividir o texto proposição por proposição. Em seguida, a observação da sucessão das proposições põe em evidência relações e formas de raciocínio. O objetivo deste nível de análise é compreender como as partes do texto são conectadas semanticamente. Já as recorrências são repetições de um mesmo tema ou da mesma palavra em contextos diferentes. No decorrer da narrativa, as recorrências espaçadas no discurso podem ser um indicador de importância, dado que a insistência de um tema ou palavra que ressurge em momentos diferentes revela o investimento psicológico da pessoa nesse tema ou palavra.

\section{Resultados e Discussão}

A análise da enunciação das narrativas construídas pelas crianças nas sessões de brincadeira permitiu visualizar vários aspectos apontados na literatura. Todas as crianças em início de tratamento relataram, como já observado por Gomes et al. (2012), Kohlsdorf e Costa (20011) e Woodgate (2006), o desconforto e o sofrimento físico decorrentes do tratamento quimioterápico. C., por exemplo, fala em uma das sessões, que o

o ruim de vir para Recife, o que tem de ruim é o tratamento, a pessoa toma remédio, ai enjoa, fica enjoado bem uns três dias, ai se a pessoa for comer num quer. E lá em casa não, eu tô enjoado, mas eu como.

A. também refere os enjôos que decorrem da quimioterapia: "É ruim [a quimioterapia] porque eu fico com enjôo, os menino tudinho bebendo água e eu não bebo". Somente uma das crianças com mais de um ano de tratamento, U., cita a quimioterapia dizendo "que é ruim porque dói".

A análise também demonstrou que as crianças em início de tratamento, devido a longos períodos de internação e intercorrências recorrentes, acabavam se apropriando da rotina hospitalar e do discurso médico, controlando as taxas relativas à imunidade, a medicação e os sintomas da doença. S., por exemplo, em uma das sessões comenta sobre uma das medicações que tem que tomar:

O nome dele é Pracstomolf. É pra tomar quatro vezes ao dia, às oito horas ... Assim, mais ou menos [se referindo ao sabor do remédio]. Eu já tomei ele, mas é tão gostosinho um pouquinho, mas arde um pouquinho.

E complementa dizendo que o remédio serve "Pra você não ter mais cansaço, ai tem que tomar todas as quantidades de cinco a dez pra você poder descansar". E conta que estava cansada "porque eu tava com leucemia ... Tava, toda vez que eu me levantava eu sentia dor nas pernas, ai eu não conseguia andar, nem pra casa da minha tia eu conseguia".

Na mesma direção, C. relata que já esteve com

pneumonia duas vezes . . . Eu já tava com pneumonia quando eu tive a primeira doença, depois passou pra outra . . Era pneumonia e é . . . Outra coisa que eu não me lembro ... Era pneumonia e anemia profunda.

Diante da narrativa de C., a pesquisadora pergunta qual foi a outra doença, a que C. responde: "Foi essa dai, o câncer...". C. também nos diz que bateu a unha na porta e que "ai arrancou [a unha]. Só que ainda bem não entrou sujeira, não é? Se entrar sujeira tem que correr de imediato pra cá". Somente uma das crianças com mais de um ano de tratamento, U., encena em seu brincar situações do contexto médico em que ele é o médico e tira o sangue da sua paciente e o coloca na máquina para fazer o exame.

São narrativas que denotam o controle excessivo que a criança precisa ter com o seu corpo, um corpo que, 
como nos disse Williams (1984), é atingido pela doença o que ocasiona uma ruptura na relação do sujeito com o mundo a sua volta. As trajetórias dessas crianças passam a ser delineadas pelos limites e cuidados com o corpo, pois qualquer deslize pode provocar infecções, baixar a imunidade, etc. Também são narrativas que relatam um corpo marcado por doenças anteriores, um corpo frágil, que precisa de cuidados.

As crianças em início de tratamento falam também das limitações e reorganizações que a doença provoca em seus cotidianos, impedindo-as muitas vezes de brincar, exigindo que fiquem longe de seus familiares. S. diz:

ontem eu ia arrumar minha piscina lá em casa, mas só que fez tanto sol, tanto sol, que eu fiquei preocupada, a minha taxa, ai mainha disse se amanhã tua taxa tiver boa eu vou chamar tua prima de novo pra vir pra cá...

C. fala que "pra sair tem que usar máscara, e eu não gosto muito de usar máscara. Fico mais dentro de casa". E refere que "Agora tá vindo e voltando pra casa, vindo e voltando" porque "as taxa não abaixa mais não, parece ... vou embora se as taxa tiver boa". Essa fala de C. denota a incerteza diante do prognóstico, esse ir e vir para o hospital, esse subir e descer das taxas. C. também nos conta sobre o ir e vir para casa construindo, como nos aponta Nicolopoulou (2005), um cenário narrativo em seu faz de conta. Neste cenário, C. monta uma ponte, que tem um buraco no meio. Essa ponte

...é pra sair lá da minha casa... Aqui eu to indo pra casa [andando com o carrinho sobre a ponte] . . esse aqui é o de volta [passa o carro pela ponte no sentido casa-hospital].

E conclui a sua história voltando para casa.

Como pode-se observar, as temáticas acima explicitadas apareceram predominantemente nas narrativas das crianças em início de tratamento. Isso pode ter ocorrido pelo fato dessas crianças estarem se deparando pela primeira vez com um longo e invasivo processo de tratamento e de modificações em seus corpos provocadas pela doença. Para essas crianças, o universo das taxas, da quimioterapia, as limitações impostas pela doença, as dores físicas, representaram situações novas, estressantes e que desorganizaram o seu cotidiano. Desorganização que requer a narrativa para ordená-la (Bruner, 1997a; Hydén, 1997; Klein; 2003; Mattingly, 1998; Murray, 2000). Desta forma, podemos dizer que essas crianças acabaram centralizando em suas narrativas referências ao que acontece com os seus corpos e às limitações decorrentes da doença como forma de organizar essas experiências.

Como já nos alertavam Almeida (2005) e Cagnin et al. (2004), as narrativas das crianças também trazem a possibilidade da morte. A análise demonstrou que duas crianças com mais tempo de tratamento finalizaram suas histórias com a morte de seus personagens. W. constrói um cenário em que os soldados estão vigiando a praia. Nesse cenário, aparecem ladrões de carro, que são mortos pelos soldados. Na sequência, os soldados morrem de infarto: "tudinho morreu", diz W. E assim ele segue incluindo novos personagens em seu brincar, que sempre morrem, o que exemplifica as recorrências constituídas em suas narrativas. W. finaliza a cena dizendo: "todo mundo morreu". U. também configura em suas brincadeiras simbólicas cenários em que seus personagens morrem no final, sendo um dos principais protagonistas uma aranha assassina. Há, porém, em uma das narrativas de U. um personagem que sobrevive ao ataque da aranha: "o homem [que] levaram pro hospital, ele viveu".

Somente uma das crianças em início de tratamento, C., apresentou narrativa acerca da morte. No entanto, ela não finalizou sua narrativa com a morte dos personagens, ao contrário, apresentou como desfecho para a sua narrativa, cuja temática era a guerra, a paz entre os personagens. Nessa trajetória de guerra e paz, C. fala que os soldados

tão morrendo de saudade [da família]. E quando morre, e a família não vê mais? Tem filhos, né? . . A família vai ficar triste, e não iam ver mais ... A maioria do povo aqui [da guerra] queria ficar em casa mais a família . . ninguém quer sair de perto da família da pessoa. E pior, se morrer, não dá pra pessoa saber. . . mas se tiver viajando assim, pode trazer o corpo pra pessoa ver, mas na guerra não.

Podemos nos perguntar a que C. se refere quando diz "tiver viajando assim". Ela estaria se referindo a estar viajando assim como ela? Sim, porque C. traz em suas brincadeiras o ir e vir para casa.

A análise das narrativas dessas crianças acerca da morte permite pensar que as crianças com mais tempo de tratamento e, consequentemente, com um contato mais prolongado com os procedimentos relativos a este, angustiam-se frente à indefinição com relação ao final de sua história (no caso, o final da sua história com o câncer). Diante da perspectiva de morte, a criança traz para as suas narrativas conteúdos acerca do que a está mobilizando, fazendo-a, portanto, querer narrar para organizar a angústia frente à possibilidade da morte como desfecho.

É importante salientar que as crianças, frente a temas intensos como a morte, recorrem ao brincar como ferramenta simbólica para a elaboração de seus medos e angústias. Isto remete ao que Goulart e Sperb (2003) apontam de que o brincar é um dos meios privilegiados utilizados pela criança para se expressar. Também esses dados vão ao encontro do que Almeida (2005) refere acerca do brincar como recurso terapêutico. Em seu estudo, Almeida relata que as crianças em suas brincadeiras matavam pessoas próximas ou da equipe médica. "Nossas crianças mataram ladrões, aranhas, soldados, animais e alguns profissionais da equipe médica".

Para W., a morte (dos seus personagens) era inevitável. U. viu no hospital um caminho para a sobrevivência de um dos seus personagens. C. reconheceu que a morte (dos personagens) acontece, mas coloca que é possível, "através de uma negociação", fazermos "um acordo de paz" e, assim, a evitarmos. Mas, C. também abriu em seu brincar a possibilidade de não "se querer viver". Ele diz: "Pra que a pessoa quer fazer guerra, né? Se todo mundo vão viver, 
Aquino, A. M., De Conti, L. \& Pedrosa, A. (2014). Construções de Significados acerca do Adoecimento e Morte nas Narrativas de Crianças com Câncer.

se não quiser viver, né?". E a pesquisadora pergunta: "É, se quiser viver tem que parar com a guerra, não é?" ao que C. responde: "Se não quiser...".

Percebe-se que as crianças através do brincar falam metaforicamente de suas experiências com a doença e com o tratamento, da realidade que enfrentam: a luta, a guerra, o combate contra o câncer. Um dos pais entrevistados para esta pesquisa relatou que um dos profissionais que explicou para seu filho acerca da leucemia utilizou-se da analogia "soldadinhos do mal que invadem o sangue, a medula". C. em uma de suas narrativas fala que toma o comprimido para "combater a doença". U. e W. também montam cenários de luta. Como vimos, U., em uma de suas narrativas, compõe uma luta entre os humanos e a aranha assassina, que morre e volta a viver, até que, finalmente, ela é morta pelo homem que levaram pro hospital. E W. monta um cenário em que soldados lutam com ladrões, depois super heróis aparecem, mas todos morrem.

Enfim, essas crianças produzem de diferentes formas sentidos sobre o adoecimento e a morte. Podemos dizer que, nesse grupo de crianças investigado, os limites impostos pela doença, o sofrimento decorrente do tratamento $\mathrm{e}$ a perspectiva da morte, são temas presentes e recorrentes em suas narrativas. As crianças em início de tratamento centralizam seus enredos narrativos no desconforto que a quimioterapia produz em seus corpos, no controle que precisam ter com a imunidade e, consequentemente, com as atividades cotidianas, pois elas não podem participar de situações que podem debilitar seu sistema imunológico. Para essas crianças, o mundo do câncer e suas consequências é novo e elas procuram, em suas narrativas, ordenar esse caos que a doença provocou em suas vidas.

Já as crianças com mais de um ano de tratamento, produziram narrativas principalmente sobre o tema da morte (dos personagens). Poucas narrativas enlaçaram o tema de procedimentos médicos. Uma possibilidade de compreensão acerca disso é que talvez para essas crianças, com mais de um ano de tratamento, os procedimentos relativos ao combate do câncer, as intercorrências e as internações não se configuram mais como algo novo em suas vidas. É como se esse universo da doença não representasse mais para elas uma ruptura em seu cotidiano. Talvez por isso, elas não precisam falar sobre o tratamento, as taxas e a distância da família, mas precisam falar sobre a possibilidade da morte, da luta incansável entre o viver e o morrer (de seus personagens).

Por outro lado, encontramos nas narrativas das crianças expectativas de melhorarem, de poderem retomar suas vidas, de voltarem para suas casas. S., por exemplo, fala que se sente triste em ficar internada,

mas tem que ficar lá ... pra tomar os remédios tudo direitinho pra eu sair do tratamento e depois eu ficar pra cá e prá lá sem tomar nenhum remédio e poder comer o que eu quiser na rua, mas só que tem que ter cuidado por causa eu to tomando essa quimioterapia.

U., ao brincar de médico, dramatiza que sua paciente está bem, que a sua saúde está boa.
É possível pensar que essas crianças ao relatarem suas expectativas e ao encenarem que os pacientes de suas histórias estavam bem, estavam falando do seu desejo de estar ou vir a estar bem diante a sua história com o adoecimento. Como diz Bruner (1997a), a narrativa lida com o material da ação e da intencionalidade humanas e, nesse sentido, ela intermedeia o mundo canônico da cultura e o mundo mais idiossincrático dos desejos.

\section{Considerações Finais}

Os resultados desse estudo possibilitam identificar duas grandes tendências. As crianças em início de tratamento organizaram suas narrativas em torno do tratamento do câncer e seus efeitos desorganizadores em relação a suas atividades cotidianas. Essas crianças tenderam a apresentar narrativas que relacionam a quimioterapia ao mal-estar que a mesma ocasiona, assim como narrativas que relacionam a sua doença a uma constante monitoração com as taxas relativas à imunidade. Já as crianças com mais de um ano de tratamento construíram cenários narrativos em que a morte dos personagens era o tema central.

Isso nos leva a refletir que tratamentos vão além dos procedimentos de cuidados exclusivos com o corpo. Estes, ao atuarem no organismo dos indivíduos, passam a assumir diversos significados para cada criança. Portanto, os diversos momentos do tratamento de câncer (o contato inicial com este e a relação continuada com o mesmo) ocasionam construções subjetivas diversas acerca da doença. Nesse sentido, é preciso dar atenção às diferentes significações que as crianças configuram acerca do seu adoecimento e a subsequente possibilidade de morte em todas as fases que o tratamento impõe. Sem considerarmos isso, talvez não sejamos capazes de compreender possíveis comportamentos decorrentes dessas construções subjetivas, tais como rejeição a certos profissionais e a certos procedimentos, choros excessivos e até comportamentos melancólicos ou depressivos. Nesse sentido, esse estudo pode contribuir nessa compreensão ao delimitar as significações de algumas crianças acerca de sua doença.

Esse estudo também permitiu esboçar a importância da composição narrativa para a criança ordenar e elaborar experiências tão desestruturantes como o câncer. Pode-se observar que nas narrativas construídas pelas crianças ao longo de suas brincadeiras e através do brincar, sentidos acerca do que estava acontecendo em suas vidas puderam ser configurados e compartilhados. Nessa direção, é importante que as instituições que atendem crianças com câncer, organizem ou mantenham espaços lúdicos em que a criança possa, através da escuta sensível de um profissional, falar de suas experiências com a doença.

Porém, os resultados dessa pesquisa, devido ao reduzido número de participantes, não permitiu a generalização analítica, conforme propõe Yin (2001). Nessa direção, sugere-se que sejam realizados estudos semelhantes que investiguem se as tendências encontradas nesse estudo podem se constituir em padrões de significação, tendo o tempo de tratamento como referência. 
Outro aspecto não contemplado nesse estudo foram as concepções dos pais sobre a doença de seus filhos. As entrevistas com os pais se restringiram a delimitar alguns dados sobre a doença da criança e o contexto familiar. Nessas entrevistas, não foram explorados, por exemplo, o que eles pensam sobre a doença de seus filhos, que estratégias eles utilizam para lidar com a mesma. Como afirmam Kohlsdorf e Costa (2011), são necessárias pesquisas que focalizem "os desafios, dificuldades e exigências específicas e características de cada período de tratamento, bem como as alterações favoráveis em padrões de comportamento dos pais ou cuidadores” (p. 228). Este também parece ser um campo investigativo frutífero.

\section{Referências}

Almeida, F. A. (2005). Lidando com a morte e o luto por meio do brincar: A criança com câncer no hospital. Boletim de Psicologia, 55(123), 149-167.

Angelo, M., Moreira, P. L., \& Rodrigues, L. M. A. (2010). Incertezas diante do câncer infantil: Compreendendo as necessidades da mãe. Escola Anna Nery Revista Enfermagem, 14(2), 301-308.

Bardin, L. (2008). Análise de conteúdo. Lisboa, Portugal: Edições 70 .

Brockmeier, J., \& Harré, R. (2003). Narrativa: Problemas e promessas de um paradigma alternativo. Psicologia: Reflexão e Crítica, 16(3), 525-535.

Bruner, J. S. (1997a). Atos de significação. Porto Alegre, RS: Artes Médicas.

Bruner, J. S. (1997b). Realidade mental, mundos possiveis. Porto Alegre, RS: Artes Médicas.

Bruner, J. S. (2001). A cultura da educação. Porto Alegre, RS: Artmed.

Bruner, J. S. (2003). Making stories: Law, literature, life. Cambridge, MA: Harvard University Press.

Cagnin, E., Liston, N., \& Dupas, G. (2004). Representação social da criança sobre o câncer. Enfermagem USP, 38(1), 51-60.

Chiattone, H. (2003). A criança e a morte. In V. Angerami (Ed.), E a psicologia entrou no hospital (pp. 69-146). São Paulo, SP: Pioneira.

Duarte, M. L. C., Zanini, L. N., \& Nedel, M. N. B. (2012). O cotidiano dos pais de crianças com câncer e hospitalizadas. Revista Gaúcha de Enfermagem, 33(3), 111-118.

Dupas, G., \& Moreira, L. (2003). Significado de saúde e de doença na percepção da criança. Revista Latino-Americana de Enfermagem, 11(6), 757-762.

Fonte, C. (2006). A narrativa no contexto da ciência psicológica sob o aspecto do processo de construção de significados. Psicologia: Teoria e Prática, 8(2), 123-131.

Gomes, I. P., Amador, D. D., \& Collet, N. (2012). A presença de familiares na sala de quimioterapia pediátrica. Revista Brasileira de Enfermagem, 65(5), 803-808.

Goulart, C. M. T., \& Sperb, T. M. (2003). Histórias de crianças: As narrativas de crianças asmáticas no brincar. Psicologia: Reflexão e Crítica, 16(2), 355-365.

Herman, D. (2003). Narrative theory and the cognitive sciences: CSLI lecture notes. Stanford, CA: Stanford University Press.

Hydén, L. (1997). Ilness and narrative. Sociology of Health and Illness, 19(1), 48-69.

Klein, K. (2003). Narrative construction, cognitive processing and health. In D. Herman, (Ed.), Narrative theory and the cognitive sciences: CSLI lecture notes (pp. 56-84). Stanford, CA: Stanford University Press.

Kohlsdorf, M., \& Costa, Á. L., Jr. (2011). Cuidadores de crianças com leucemia: Exigências do tratamento e aprendizagem de novos comportamentos. Estudos de Psicologia (Natal), 16(3), 227-234.

Kóvacs, M. J. (1992). Morte e desenvolvimento humano. São Paulo, SP: Casa do Psicólogo.

Macedo, L., \& Sperb, T. (2007). O desenvolvimento da habilidade da criança para narrar experiências pessoais: Uma revisão da literatura. Estudos de Psicologia (Natal), 12(3), 233-241.

Mattingly, C. (1998). Healing dramas and clinical plots. The narrative structure of experience. New York: Cambridge University Press.

Moutinho, K., \& De Conti, L. (2010). Considerações sobre a psicologia da arte e a perspectiva narrativista. Psicologia em Estudo (Maringá), 15(4), 685-694.

Murray, M. (2000). Levels of narrative analysis in health psychology. Journal of Health Psychology, 5(3), 337-347.

Nehmy, R. M. Q., Brito, A. C., Mota, J. A. C., \& Oliveira, B. M. (2011). A perspectiva dos pais sobre a obtenção do diagnóstico de leucemia linfóide aguda em crianças e adolescentes: Uma experiência no Brasil. Revista Brasileira Saúde Materno Infantil, 11(3), 293-299.

Nicolopoulou, A. (2005). Play and the narrative in the process of the development: Commonalities, differences and interrelations. Cognitive Development, 20(4), 495-502.

Nunes, D. C., Carraro, L., Jou, G. I., \& Sperb, T. M. (1998). As crianças e o conceito de morte. Psicologia: Reflexão e Crítica, 11(3), 579-590.

Perrone, M. (1992). Desenvolvimento do discurso narrativo. São Paulo, SP: Martins Fontes.

Santo, E. A. R. E., Gaíva, M. A. M., Espinosa, M. M., Barbosa, D. A., \& Belasco, A. G. S. (2011). Cuidando a criança com câncer: Avaliação da sobrecarga e qualidade de vida dos cuidadores. Revista Latino-Americana Enfermagem, 19(3). Recuperado em 26 de janeiro, 2013, em http://ead.eerp.usp. br/rlae

Silva, F. A. C., Andrade, P. R., Barbosa, T. R., Hoffmann, M. V., \& Macedo, C. R. (2009). Representação do processo de adoecimento de crianças e adolescentes. Escola Anna Nery Revista Enfermagem, 13(2), 334-41.

Torres, W. C. (2002). O conceito de morte em crianças portadoras de doenças crônicas. Psicologia: Teoria e Pesquisa, 18(2), 221-229.

Torres, W. C., Guedes W., Ebert, T., \& Torres, R. (1998). Algumas contribuições à pesquisa sobre a morte. In R. M. S. Cassorlla (Ed.), Da morte: Estudos brasileiros (pp. 131-144). São Paulo, SP: Papirus.

Vieira, A., \& Sperb, T. (1998). O brinquedo simbólico como uma narrativa. Psicologia: Reflexão e Crítica, 11(2), 233-252.

Williams, G. (1984). The genesis of chronic illness. Sociology of Health and Illness, 6(2), 174-200.

Woodgate, R. (2006). Life is never the same: Childhood cancer narratives. European Journal of Cancer Care, 15(1), 8-18.

Yin, R. (2001). Estudo de caso: Planejamento e métodos. Porto Alegre, RS: Bookman. 